\title{
Conservation challenge by global change
}

\author{
E. A. B. Feldmeyer-Christe
}

Swiss Federal Research Institute WSL, Zürcherstrasse 111, CH-8903 Birmensdorf, Switzerland.

E-mail: elizabeth.feldmeyer@wsl.ch

\section{Introduction}

This issue contains 13 papers presented at the International Conference "Monitoring the effectiveness of nature conservation", held 3-6 September 2007 in the Swiss Federal Institute for Forest, Snow and Landscape Research WSL in Birmensdorf, Switzerland.

The conference is a part of the worldwide effort to stop the ever-increasing degradation of the natural environment. This is being increasingly threatened by climate change, high population density and intensification of agriculture, which leads to a worldwide decline of species and habitat diversity. At the same time, in the industrialized countries there is an increasing awareness of the value of ecosystem functions that provide social well-being and economic benefits and of the necessity to preserve it (O'Riordan and Stoll-Kleemann 2002). The need for nature conservation is no more a controversial theme in the developed countries but there is still no consensus on what exactly nature is, what kind of nature has to be preserved and how it has to be done. Europeans as well as Japanese view the natural environment as a product of human activity while a number of people, including Americans and Australians, regard nature only as an environment untouched by any human activity (Hodge 2000). In the first case, farmers have to pursue traditional management on lands that would otherwise returned to forest while in the second case farmers are paid to return farmland to wilderness.

In Central Europe, wild nature has not existed for a long time, except in areas above the timberline, in pristine mires and floodplains of rivers. Our countryside shows the imprint of centuries of agricultural practices. By creating new landscapes, traditional agriculture and forestry contributed to a huge increase of species diversity by offering additional habitats for flora and fauna. A striking example of man's imprint can be seen in the Netherlands where people have won agricultural fields from the sea. Since the middle of the $20^{\text {th }}$ century the intensification of agriculture, by altering the less productive land, unfortunately has led to an inverse effect and to an impoverishment of flora and fauna. The nature we want to see and to preserve today in Europe is actually the rural landscape of the $19^{\text {th }}$ century, with its patchwork of fields, meadows, rivers and woods favouring high species diversity.

Nature conservation projects started at the beginning of the $20^{\text {th }}$ century with the creation of national parks and nature reserves. The aim was to shelter some areas from the influ- ence of new intensified agricultural practices and the effects of urbanization. At present, nature protection measures are implemented in different ways and different legal contexts in all European countries.

For example, in the Natura 2000 network, governments of the European Union adopted legislation aimed to protect the most seriously threatened habitats and species and developed programmes to achieve this aim. Another way to slow down the agricultural pressure and the associated loss of species diversity is the implementation of Agri-Environmental Schemes (AES). The main environmental impacts of agriculture on the environment are soil erosion, water quality degradation and wildlife habitats loss. Agri-environmental schemes provide programmes to encourage farmers to adopt environmentally beneficial practices on their land. The aim is to enhance biological diversity across a range of plant and animal groups, including pollinators. The cost to the farmer in supplying these environmental services is compensated through payments.

All these conservation measures require monitoring to determine to what extent the different nature conservation measures for maintaining the quality of protected ecosystems are successful. And there is a growing demand for monitoring the effectiveness of protection measures as more international money is spent on nature conservation programmes.

Scientists are aware of this issue and have developed in the last few decades technological and biological know-how. The conference presented a large panel of methods aimed to quantify biodiversity, to detect changes with ever more powerful remote sensing methods and to perform data analyses with impressive statistical tools.

\section{Monitoring at the national and international level}

The Swiss mire monitoring is a good example of a successful nation-wide monitoring (Ecker et al., this issue). On the basis of a statistical sampling of Swiss mires of national importance the results are valid for the entire area of Switzerland. To identify vegetation structure and vegetation change, the monitoring deals with predictive vegetation mapping that combines image classification and predictive habitat distribution models. The use of remote sensing data allows saving money by reducing time-consuming fieldwork. Developed for the Swiss mires, the monitoring method might be applicable over a large range of biotopes and has the potential to 
become a standard method to monitor the priority habitats in Europe.

Since 1994 the European Union has adopted a common nature and biodiversity policy. The conservation programme Natura 2000 has the aim to establish a EU-wide network of nature protection areas to assure the long-term survival of Europe's most valuable and threatened species and habitats.

Rosati et al. (this issue) tested the effectiveness of the Natura 2000 programme in Italy. They used potential natural vegetation (PNV) as a tool to compare the Natura 2000 sites with the national network of protected areas (OLPA). By means of a gap analysis, they showed that the representativeness of PNV types is better in the European network than in the national network.

The need of standardised methods for the monitoring of Natura 2000 was a key topic in the conference. Förster et al. (this issue) present a straightforward approach to derive Natura 2000 habitats in Germany using newly developed methods of classification of high-resolution Quickbird images.

\section{Quantifying diversity}

A current approach to assess the effectiveness of conservation measures is to quantify and monitor species diversity. Different approaches were discussed in the conference. In the background, there is always the necessity to save time and money and simultaneously not to lose too much accuracy. The use of remote sensing in plant ecology allows reducing the investments in fieldwork and so the global cost of a monitoring. Rocchini et al. (this issue) presented a powerful remote sensing tool (rarefaction of reflectance value) for quantifying the diversity of an area from local ( $\alpha$-diversity) to regional scale ( $\beta$ - and $\gamma$-diversity) as an alternative to standard plant inventories that are more costly. The authors nevertheless concluded that remote sensing should aid but not replace standard plant surveys.

The choice of indicators is fundamental in evaluation processes. Tropek et al. (this issue) used beetles and spiders as indicators to assess the ecological value of post-industrial quarries in Czech Republic and demonstrated that ecologically similar groups can give different results regarding the estimation of species richness. They hence recommended a multi-taxa approach to evaluate biodiversity. Chiarucchi et al. (this issue) used vascular plants for assessing biodiversity and proposed a probabilistic sampling approach to monitor species diversity within a regional network of protected areas. In their study of sal forests in Bangladesh, Rahman et al. (this issue) limited the indicator choice to a single species, the dominant tree Shorea robusta, to assess the spatial and structural diversity of forests. The strength of the method lies in its simplicity, which is to compute some indices that are based on 5 trees from each plot. The method can be used in quick-and-dirty assessments of large forests and can also be used to analyse large databases.

Another important question is how sensitive the performance of the selected indicators is to the scale of measuring, both in taxonomic terms as in terms of plot size. In their paper Marignani et al. (this issue) assessed the effect of changing indicators (taxonomic resolution, life and growth form, indicator species), plot size and data transformation in discriminating between different plant communities. Changing plot size does not much influence their ability to discriminate among the habitats types investigated, while indicator species show the best discriminating power.

The subject of limited detectability in monitoring surveys also needs some attention. Kéry and Schmidt (this issue) discussed this topic by presenting two interesting case studies in Switzerland: the distribution of slow worms and of breeding birds.

\section{Management effect}

Several contributions addressed the topic of the effectiveness of agri-environmental schemes (AES), a hot topic since such success controls of cost-intensive management measures are urgently needed. Schindler et al. (this issue) explored the effects of AES in Austria on landscape value and biodiversity and recommend a better adjustment to specific conservation measures. Mayer et al. (this issue) investigated the control of success of applied AES in Bavarian grasslands on plant species diversity and productivity and concluded that the most effective programmes are those associated with a real management change.

Virágh et al. (this issue) presented the performances of the Juhász-Nagy's coenological functions family (based on the information theory methods), for an impact monitoring in different stands of Brachypodium pinnatum dominated grasslands in Hungary. They demonstrated that the use of fine-scale quantitative methods, which considers spatial organization of plant individuals (spatial variability and spatial dependence of species), could be effective to monitor plant community responses to management over long periods. Batáry et al. (this issue) analysed if the arthropod diversity in agriculturally used landscapes depends on the degree of disturbance intensity.

The conference provided scientific information on the effectiveness of conservation measures that are of high relevance for nature conservation policies and society and it highlighted the need for a standardisation of methods at the international level. Because there is actually no doubt that monitoring will have an ever more important role to play in a world where the human population continues to increase dramatically.

\section{References}

Hodge, I. 2000. Agri-environmental relationships and the choice of policy mechanisms. The World Economy 23:257 - 273.

O'Riordan, T. and S. Stoll-Kleemann. 2002. Biodiversity, Sustainability and Human Communities. Cambridge University Press, Cambridge. 